SUPPORTING INFORMATION

\title{
Mechanism of Electrospray Supercharging for Unfolded Proteins: Solvent-Mediated Stabilization of Protonated Sites During Chain Ejection
}

\author{
Insa Peters, Haidy Metwally, and Lars Konermann* \\ Department of Chemistry, The University of Western Ontario, London, Ontario, \\ N6A 5B7, Canada. \\ * corresponding author: konerman@uwo.ca
}

This file contains:

\section{Supporting Figures}

Figure $\mathrm{S} 1$ : Solution phase titration curve of $\mathrm{aMb}$.

Figure S2: Continuation of Figure 2 (lower charge states).

Figure S3: Experimental spectra, showing sulfolane adducts at different cone voltage.

Figure S4: CEM evaporation kinetics.

Figure S5: Radial distribution functions of sulfolane/water droplets.

Figure S6: Example of $\mathrm{Na}^{+}$ejection via the IEM.

Figure S7: CEM runs for $\mathrm{aMb}^{30+}$ and $\mathrm{aMb}^{33+}$.

Figure S8: Examples of less typical CEM runs for $\mathrm{aMb}^{33+}$.

Figure S9: Experimental IMS data and MD gas phase structures.

Figure S10: Details of electrostatic toy model.

\section{Supporting Movies}

Movie 1: CEM of $\mathrm{aMb}^{27+}$, water droplet.

Movie 2: CEM of $\mathrm{aMb}^{27+}$, water/sulfolane droplet. 


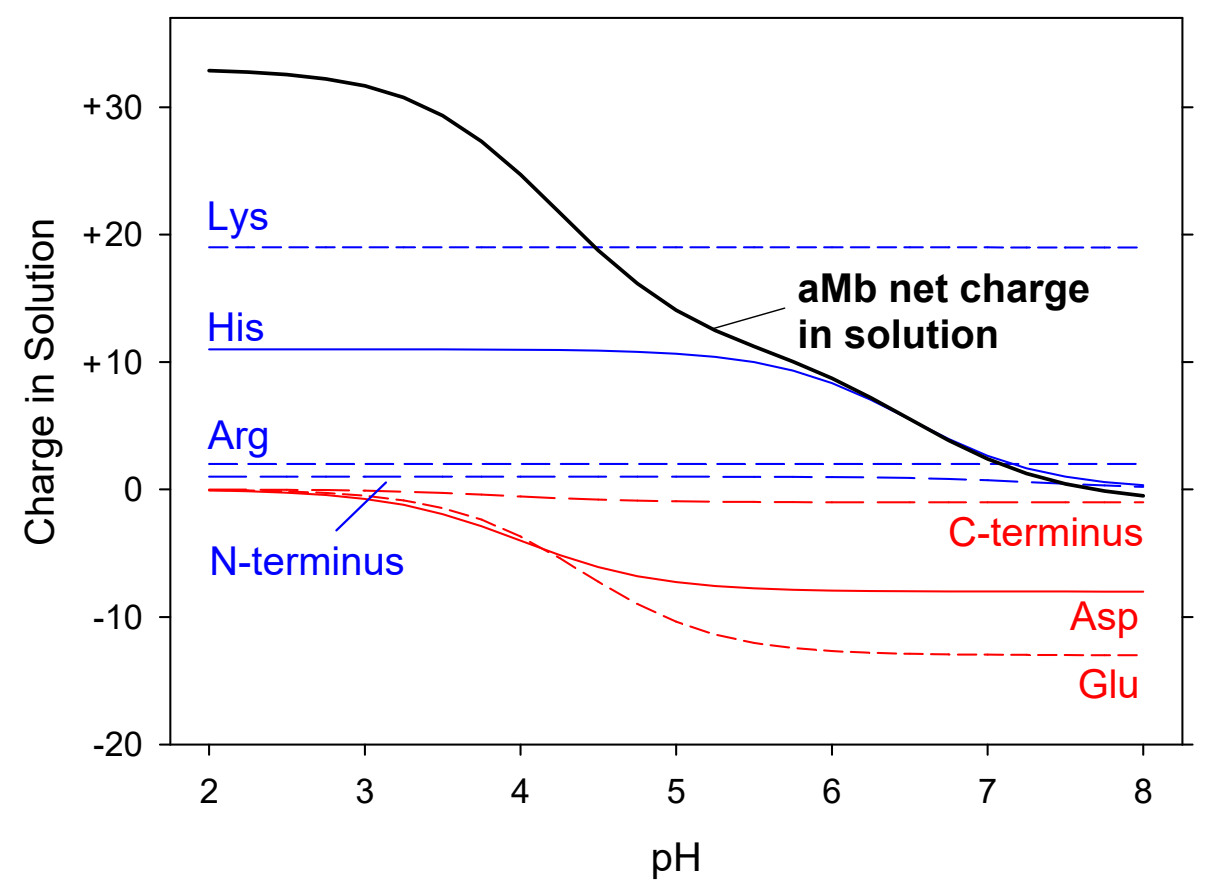

Figure S1. Calculated aMb titration profile, displaying the net charge of the protein in solution vs. $\mathrm{pH}$ (black). Also shown are the contributions of titratable sites, weighted by their abundance in the protein sequence. The number of sites and their $\mathrm{pK}_{\mathrm{a}}$ values are: $1 \mathrm{~N}_{\text {-terminus }}^{+}(7.4) ; 2 \mathrm{Arg}^{+}(12.0)$; $19 \mathrm{Lys}^{+}$(10.8); $11 \mathrm{His}^{+}$(6.5); 8 Asp (4.0), $13 \mathrm{Glu}$ (4.4), $1 \mathrm{C}$-terminus (3.9). Modified from ref. ${ }^{1}$ 


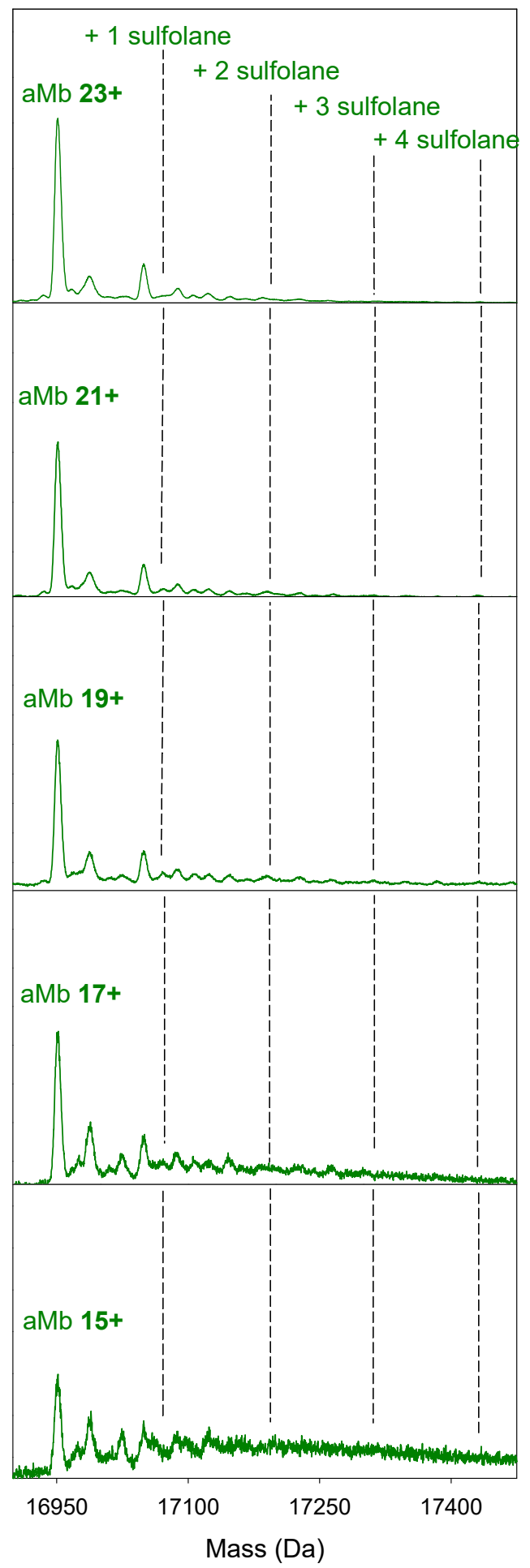

Figure S2. Continuation of Figure 2 (main text), focusing on lower charge states. This figure shows $\mathrm{aMb} 23+$ to $15+$ produced by denatured supercharging ESI with gentle source settings. While the highest charge states (Figure 2e-h in the main text) carry conspicuous sulfolane adducts $(\Delta M=120 \mathrm{Da})$, no such adducts are present for the lower charge states depicted here. 


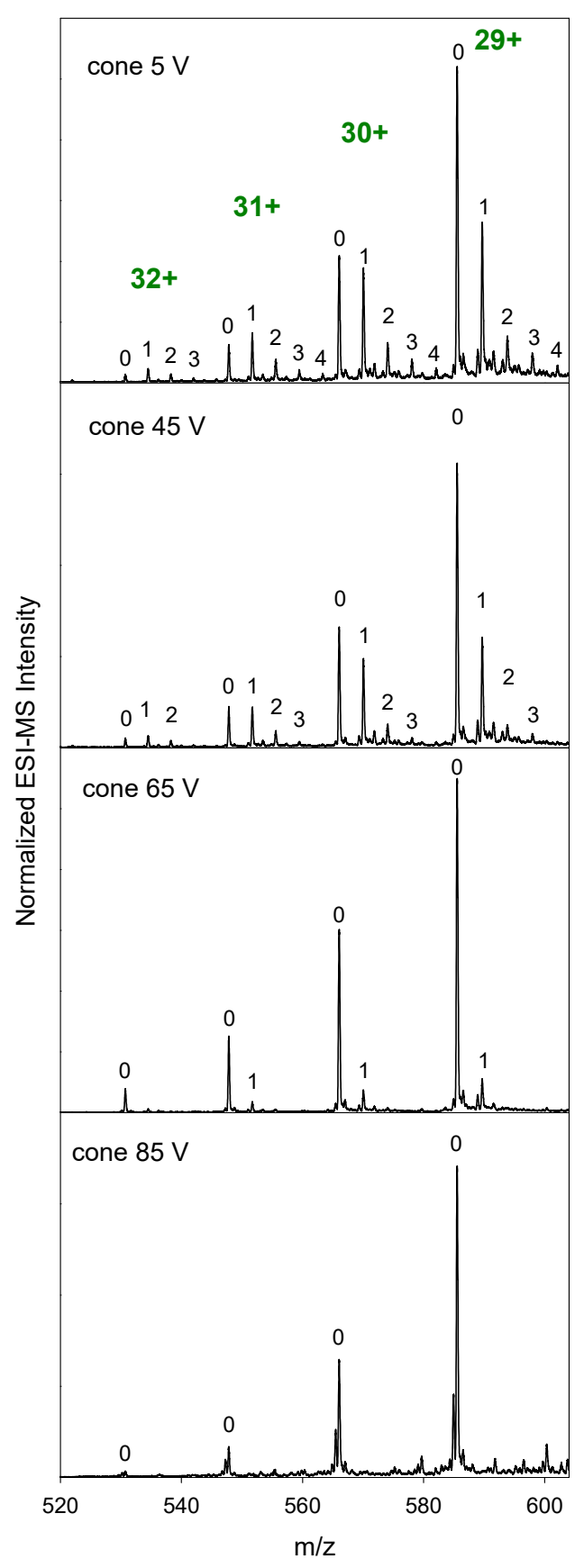

Figure S3. Mass spectra of aMb generated by denatured supercharging ESI (water, $0.1 \%$ formic acid, $1 \%$ sulfolane). This figure focuses on highly charged ions (32+ to 29+). 1, 2, 3, 4 indicate the number of sulfolane molecules adducted to the protein. Data were acquired at different cone voltage, between $5 \mathrm{~V}$ ("gentle") and $85 \mathrm{~V}$ ("harsh"). Increasing cone voltage caused loss of sulfolane adducts as a result of collisional heating. For the spectra shown here the temperatures in the ion sampling interface were kept low (source $25^{\circ} \mathrm{C}$, desolvation gas $40{ }^{\circ} \mathrm{C}$ ). At cone $=85 \mathrm{~V}$ the most highly charged ions $(32+, 31+)$ start to disappear from the spectrum as a result of collision-induced dissociation (CID), i.e., rupture of covalent bonds. The susceptibility of these highly charged protein ions to CID reflects the fact that source activation is proportional to the charge state $z .^{2}$ 

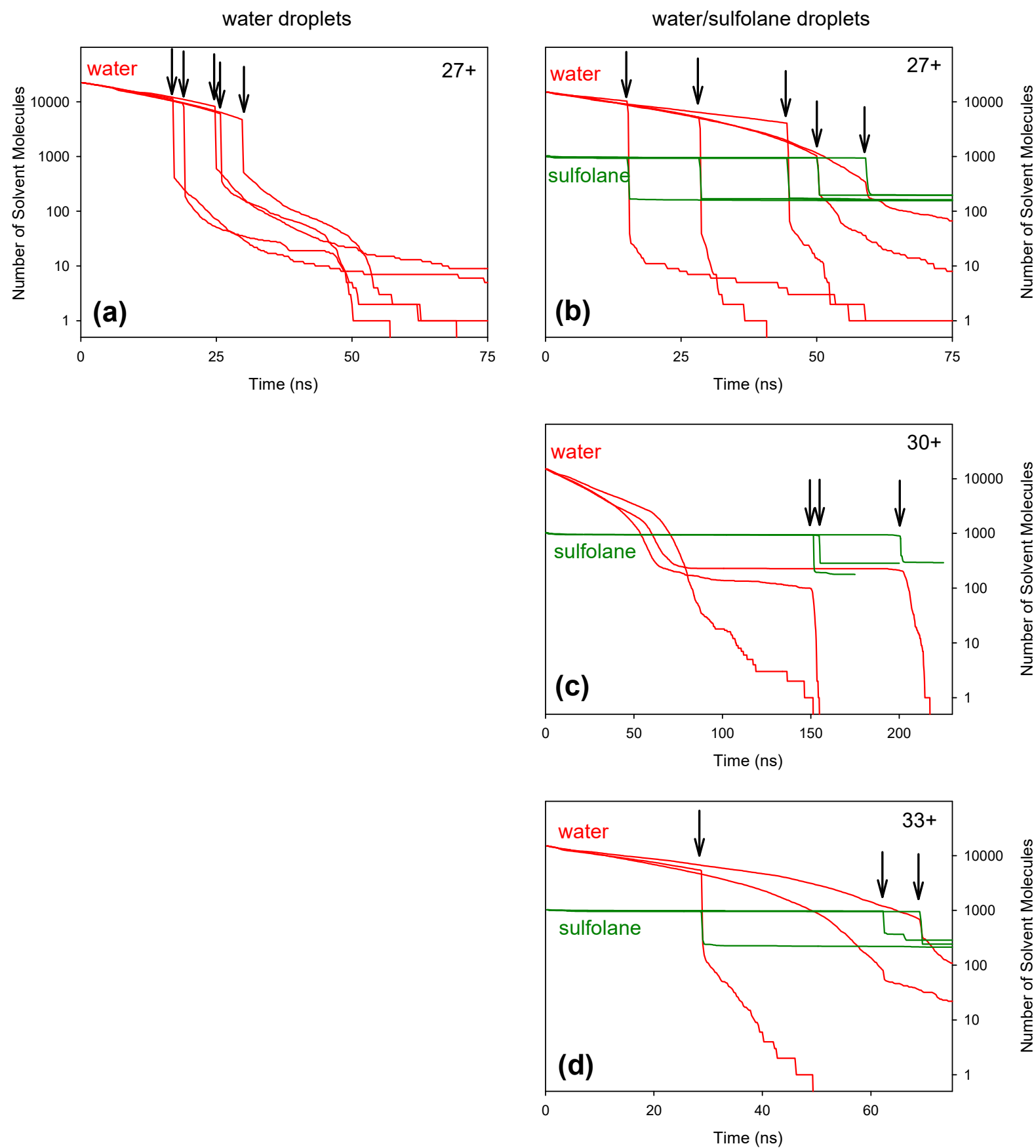

Figure S4. MD simulation results, displaying the number of solvent molecules in the system during CEM from water droplets (a) and water/sulfolane droplets (b-d). Each panel shows data for multiple runs. Vertical arrows indicate the instant where the protein separated from the droplet. Different $\mathrm{aMb}$ charge states were tested, 27+ (a, b), 30+ (c), and 33+(d). Droplet runs that had not produced a free protein after $75 \mathrm{~ns}$ were extended for another $75 \mathrm{~ns}$ at $370 \mathrm{~K}$, followed by $50 \mathrm{~ns}$ at $450 \mathrm{~K}$. In three simulations (one $30+$ run and two 33+ runs, not shown) the protruding protein tail did not separate from the droplet within the simulation time window. 


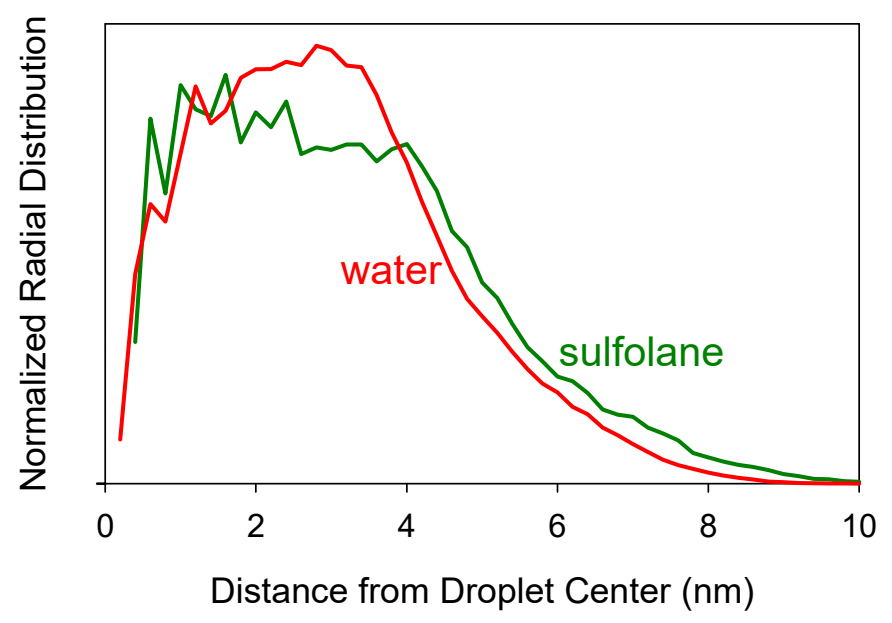

Figure S5. Radial distribution of solvent molecules in water/sulfolane droplets containing $\mathrm{aMb}$ $27+$ averaged over five runs. These data reflect the situation after equilibration, prior to eruption of the protein from the droplet surface. 


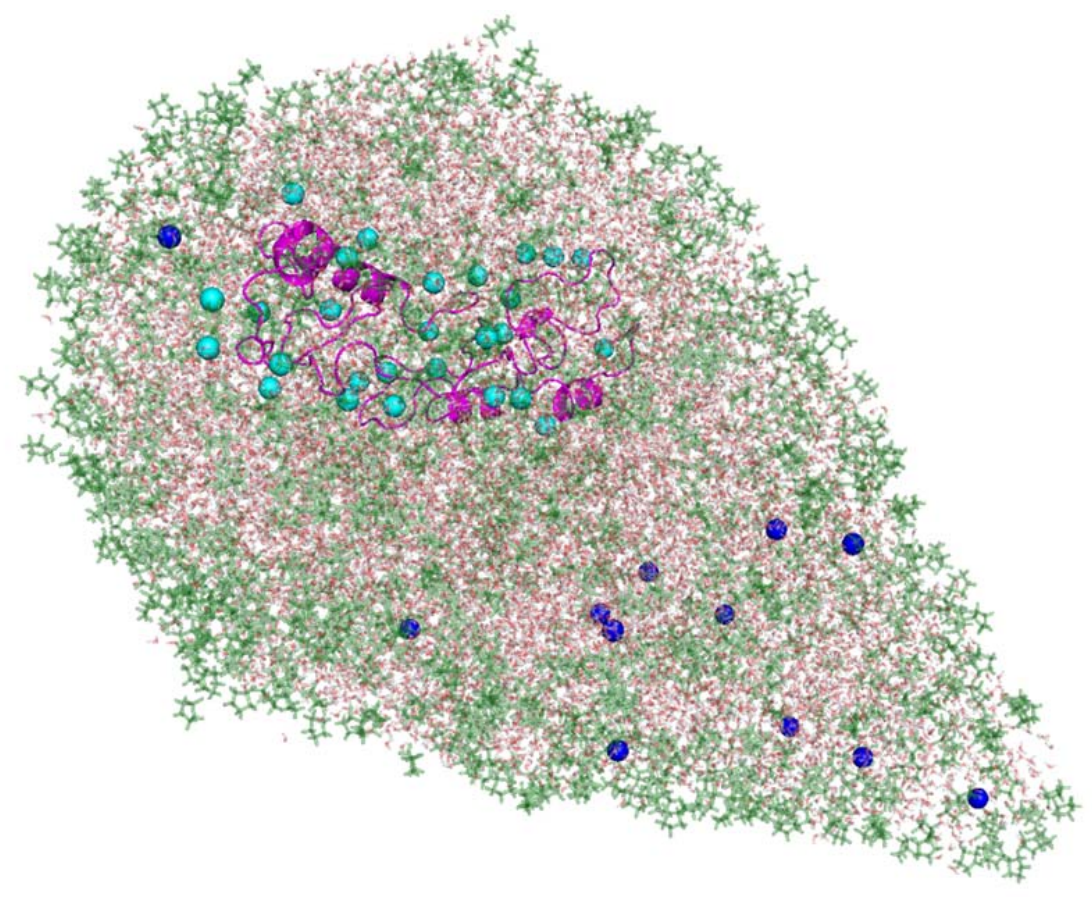

Figure S6. Example of an IEM event, i.e., ejection of solvated $\mathrm{Na}^{+}$(blue) from a water/sulfolane droplet containing $\mathrm{aMb}^{27+}$ at $t=1.5 \mathrm{~ns}$. Electrostatic repulsion has pushed most of the $\mathrm{Na}^{+}$into the bottom right portion of the droplet, while the $27+$ protein occupies the upper left. Positive charges on the protein are indicated in cyan, sulfolane is green, water oxygen is red. 


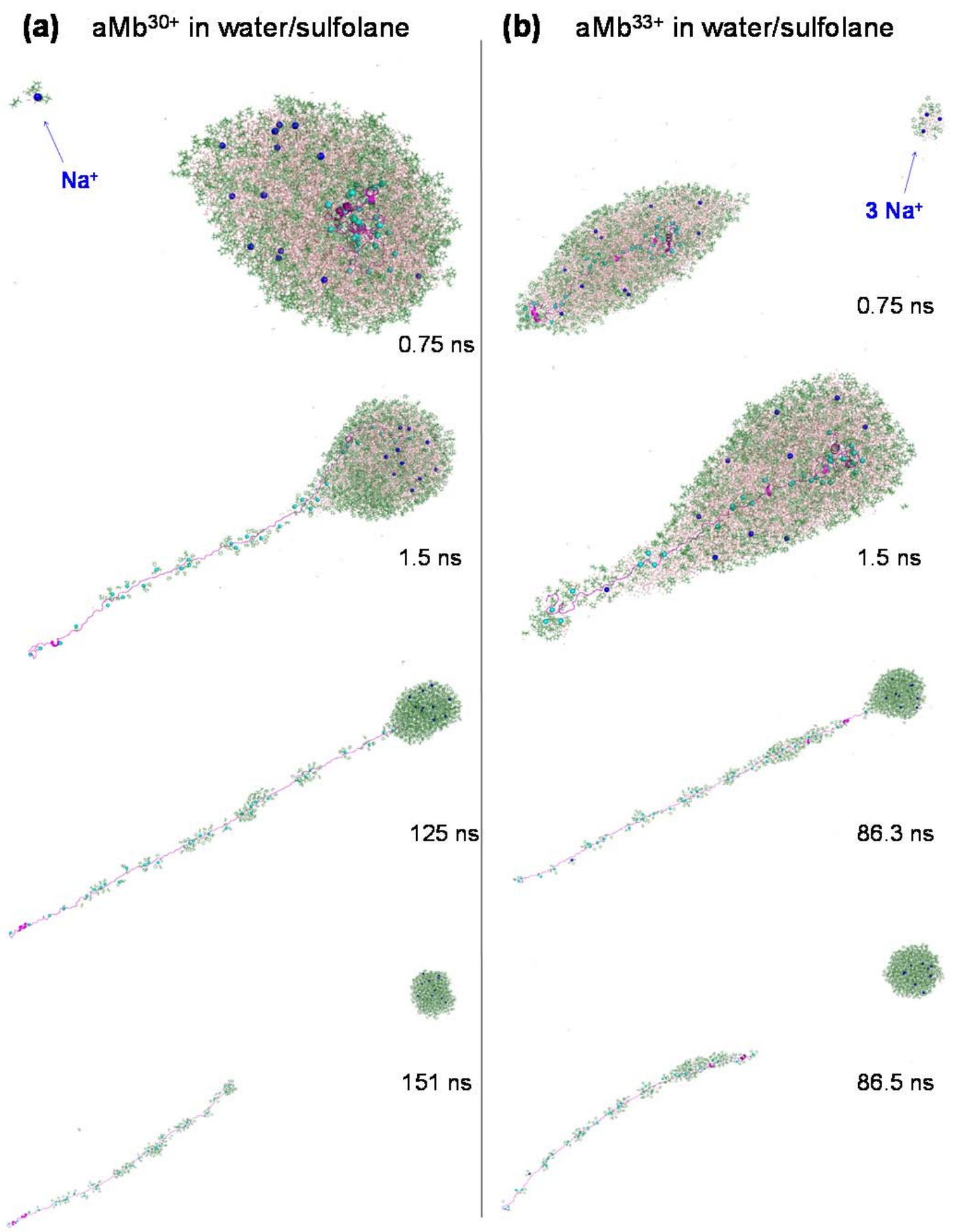

Figure S7. MD snapshots, illustrating typical CEM behavior for (a) $\mathrm{aMb}^{30+}$ and (b) $\mathrm{aMb}^{33}+$ in water/sulfolane droplets. Coloring is as in the previous figure. Early events include the IEM ejection of solvated $\mathrm{Na}^{+}$(a, top), and the release of a small progeny droplet containing three $\mathrm{Na}^{+}(\mathrm{b}$, top). Compared to the $\mathrm{aMb}^{27+}$ data of Figure $3 \mathrm{~b}$ (main text), the droplets shown here undergo more water evaporation before separating from the protein. Note the abundance of sulfolane (green) on the protruding chains. As discussed in the main text, this solvation stabilizes charged sites on the protein and represents a central element of the CEM supercharging mechanism. 
(a) $\mathrm{aMb}^{33+}$ in water/sulfolane
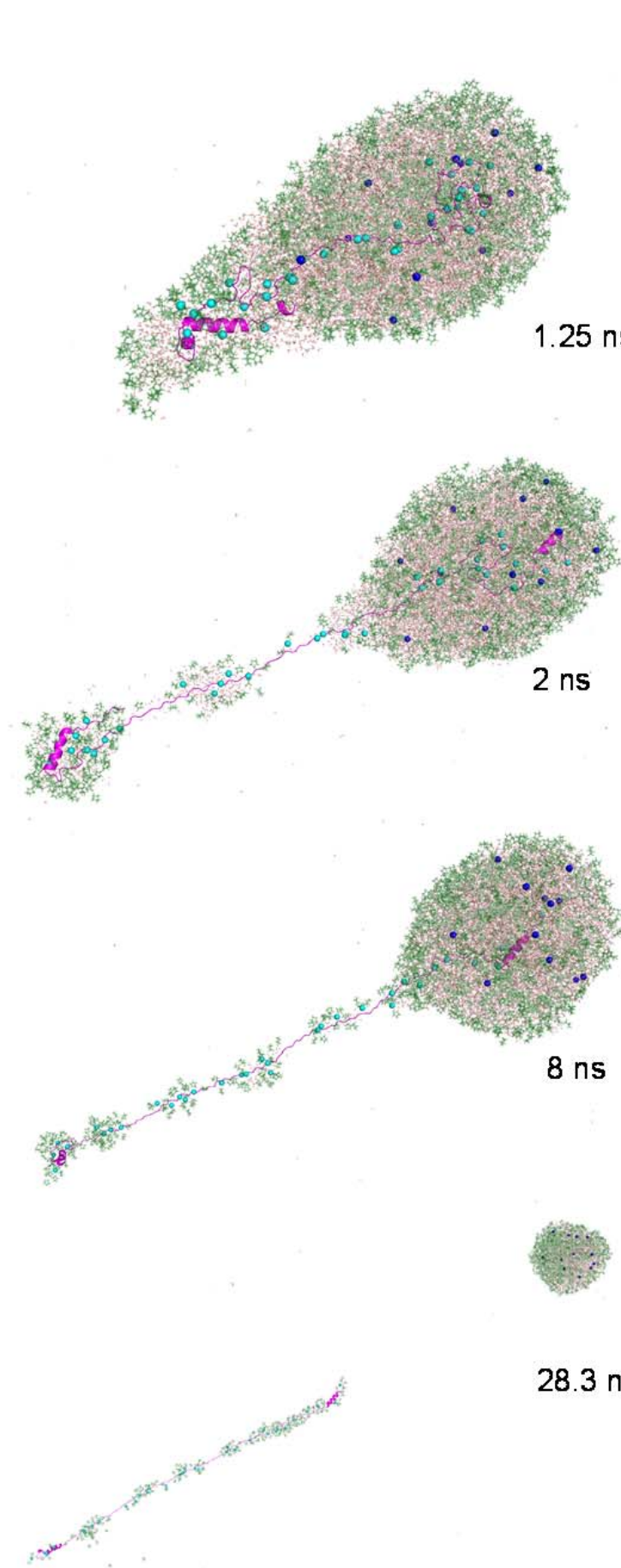

(b) $\mathrm{aMb}^{33+}$ in water/sulfolane

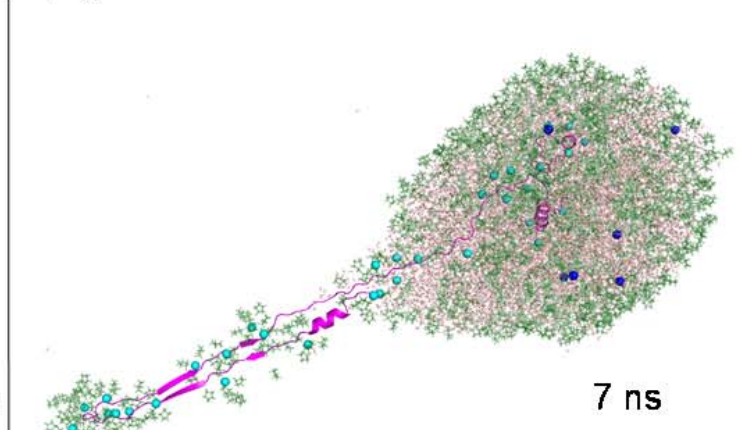

159 ns

Figure S8. Additional MD data for $\mathrm{aMb}^{33+}$ in water/sulfolane droplets, illustrating less common ESI behavior. (a) The protruding chain initially remains attached to a small progeny droplet (top), prior to undergoing typical CEM events. (b) The protein erupts from the droplet surface in a hairpin conformation that subsequently opens up and produces an extended chain. In this particular run the protein did not separate from the droplet; instead, the droplet dried out while the chain remained attached. The behavior seen in (b) may be interpreted as a CEM/CRM hybrid scenario. ${ }^{3}$ 

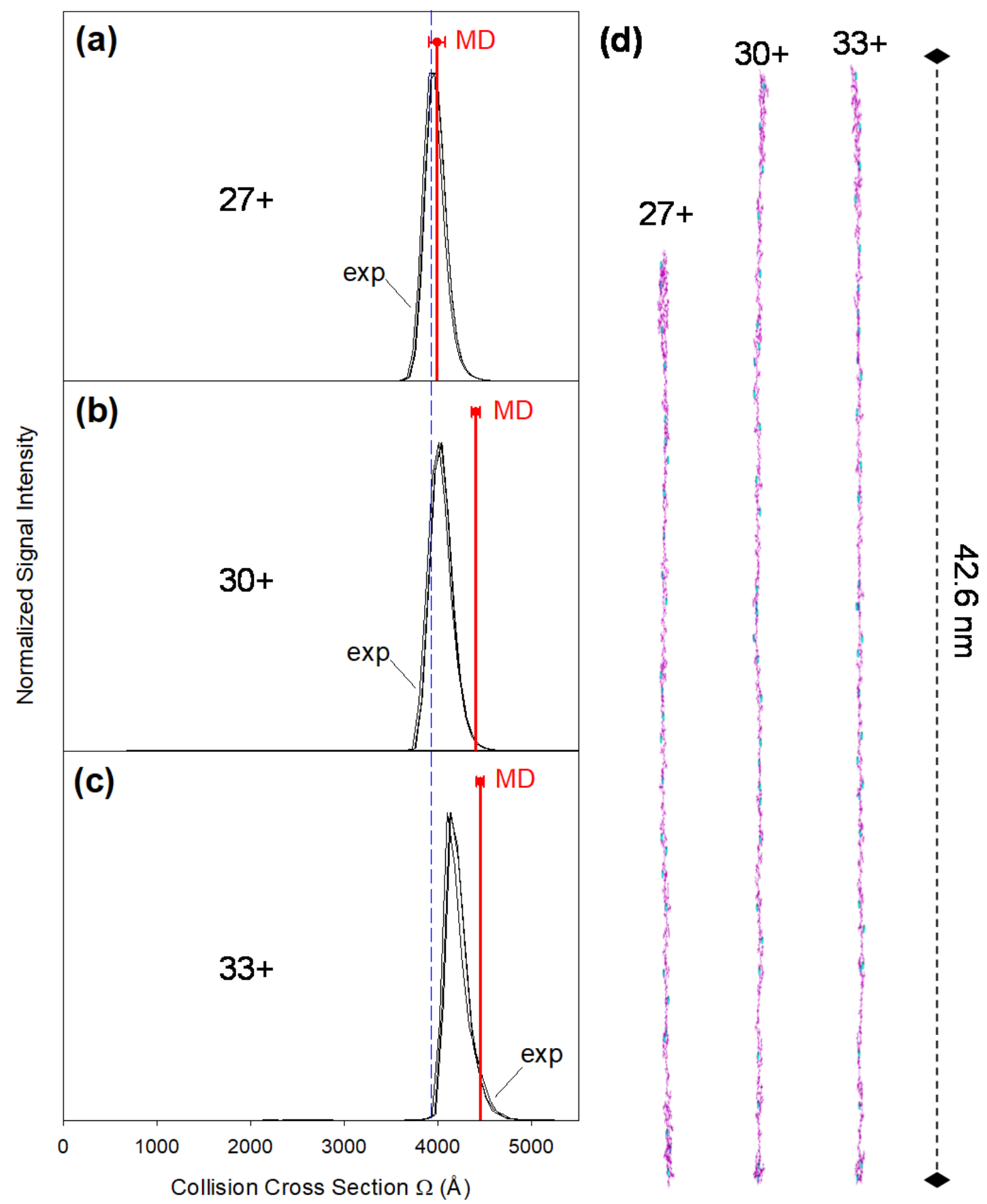

Figure S9. Experimental and MD gas phase conformations of aMb charge states $27+, 30+$ and $33+$ generated by denatured supercharging ESI. Panels (a) - (c) display experimental $\Omega$ values (black, overlays of three independent IMS measurements). Red vertical lines represent the $\Omega$ values of MD structures (averaged between $100 \mathrm{~ns}$ and $500 \mathrm{~ns}$ after release from water/sulfolane droplets). The blue dashed line helps guide the eye, highlighting the slight expansion of the protein ions with increasing charge state. (d) Examples of gas phase structures 500 ns after release from water/sulfolane droplets. These structures are shown at the same zoom level, defined by the scale bar on the right. Differences in apparent length mainly arise from more or less extensive loop formation at the $\mathrm{N}$ - and $\mathrm{C}$-termini. 


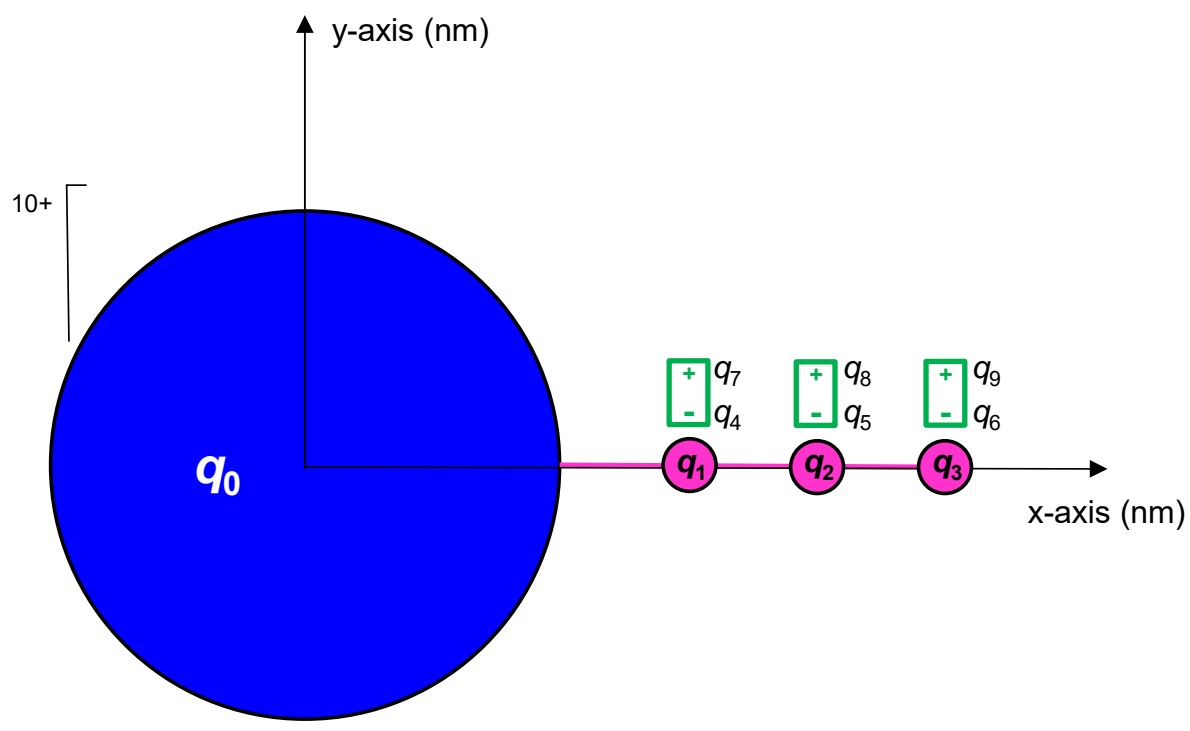

Figure S10. CEM supercharging toy model from Figure 6 (main text). Electrostatic calculations are analogous to those used for earlier bead chain models. ${ }^{4,5}$ The overall charge of $10+$ is distributed among the conducting spheres \#0 (droplet), and \#1, \#2, \#3 (basic protein residues). The corresponding charges are $q_{0}, q_{1}, q_{2}$, and $q_{3}$. These four $q_{\mathrm{i}}$ values were determined by minimizing the total electrostatic energy $E_{\mathrm{el}}$ using Microsoft Excel Solver

$$
E_{e l}=\frac{1}{8 \pi \varepsilon_{0}} \sum_{i=0}^{3} \frac{q_{i}^{2}}{r_{i}}+\frac{1}{4 \pi \varepsilon_{0}} \sum_{i=0}^{8} \sum_{j=i+1}^{9} \frac{q_{i} q_{j}}{r_{i j}}
$$

The $r_{\mathrm{i}}$ in this expression represent radii of beads $0-3$, while $r_{\mathrm{ij}}$ refers to midpoint distances of charged sites. Solvent dipole moments were chosen to match either water or sulfolane. Two charges $+\mathrm{e} /-\mathrm{e}$ that are $1 \AA$ apart have a dipole moment of $4.8 \mathrm{D}^{6}{ }^{6}$ Thus, water $(1.85 \mathrm{D})^{7}$ was modeled as $+0.39 \mathrm{e} /-0.39 \mathrm{e}$ spaced by $1 \AA$, and sulfolane $(4.7 \mathrm{D})^{8}$ was modeled as $+0.98 \mathrm{e} /-0.98 \mathrm{e}$ spaced by $1 \AA$. All other system parameters are summarized in the following table.

\begin{tabular}{|l|l|l|l|l|l|}
\hline site number & $\mathbf{x}(\mathbf{n m})$ & $\mathbf{y}(\mathbf{n m})$ & radius $(\mathbf{n m})$ & charge $\boldsymbol{q}_{\mathbf{i}}$ & charge $\boldsymbol{q}_{\mathbf{i}}$ \\
\hline 0 & 0 & 0 & 2 & $10-q_{1}-q_{2}-q_{3}$ & \\
\hline 1 & 3 & 0 & 0.2 & (Excel Solver) & \\
\hline 2 & 4 & 0 & 0.2 & (Excel Solver) & \\
\hline 3 & 5 & 0 & 0.2 & (Excel Solver) & \\
\hline 4 & 3 & 0.25 & point charge & -0.39 (water) & -0.98 (sulfolane) \\
\hline 5 & 4 & 0.25 & point charge & -0.39 (water) & -0.98 (sulfolane) \\
\hline 6 & 5 & 0.25 & point charge & -0.39 (water) & -0.98 (sulfolane) \\
\hline 7 & 3 & 0.35 & point charge & +0.39 (water) & +0.98 (sulfolane) \\
\hline 8 & 4 & 0.35 & point charge & +0.39 (water) & +0.98 (sulfolane) \\
\hline 9 & 5 & 0.35 & point charge & +0.39 (water) & +0.98 (sulfolane) \\
\hline
\end{tabular}

Charge-dipole interactions are more favorable in the presence of sulfolane, causing the protein charge $q_{\text {protein }}=q_{1}+q_{2}+q_{3}$ to be $25 \%$ greater than for water (see Figure 6 , main text). This $25 \%$ charge increase is mechanistically analogous to supercharging under denaturing ESI conditions, where protein ions are generated via the CEM. 


\section{SI References}

(1) Metwally, H.; Duez, Q.; Konermann, L. Anal. Chem. 2018, 90, 10069-10077.

(2) Thomson, B. A. J. Am. Soc. Mass Spectrom. 1997, 8, 1053-1058.

(3) Beveridge, R.; Phillips, A. S.; Denbigh, L.; Saleem, H. M.; MacPhee, C. E.; Barran, P. E. Proteomics 2015, 15, 2872-2883.

(4) Sciuto, S. V.; Liu, J.; Konermann, L. J. Am. Soc. Mass Spectrom. 2011, 22, 1679-1689.

(5) Konermann, L. J. Am. Soc. Mass Spectrom. 2009, 20, 496-506.

(6) Atkins, P. Physical Chemistry, 10th ed.; W. H. Freeman \& Co.: New York, 2010.

(7) Liu, H. C.; Wang, Y. M.; Bowman, J. M. J. Phys. Chem. B 2016, 120, 1735-1742.

(8) Tilstam, U. Org. Process Res. Dev. 2012, 16, 1273-1278. 